\title{
El sistema urbano de los países del Río de la Plata
}

\author{
Antonio Zárate Martín ${ }^{*}$
}

\section{LAS BASES DE LA RED URBANA}

Con unas tasas de población urbana en 1985 del 85 por 100 en Uruguay y del 84 en Argentina, comparables a las de Europa o Estados Unidos, y de sólo el 41 por 100 de población urbana en Paraguay por su carácter rural, las ciudades de los países del Plata se distribuyen de forma muy desequilibrada desde los puntos de vista espacial y jerárquico: forman redes incompletas, con fenómenos de macrocefalia y cortocircuito funcional, que dificultan el acceso de la población a los servicios básicos y la difusión del desarrollo económico y de las innovaciones técnicas y culturales, agravando las contradicciones de una economia y espacio dual.

Esta distribución de ciudades, muy concentradas espacialmente, centralizada y radioconcéntrica desde el punto de vista funcional, es ante todo una herencia de los modelos de ocupación del territorio que se han sucedido a través del tiempo.

De este modo, las ciudades principales, que constituyen la base de la trama urbana actual, datan de la época de la colonización. Respondieron a la necesidad de apoyo de los establecimientos mineros del altiplano andino, al control del bajo Paraná, en la frontera con las posesiones portuguesas, $y$ al anhelo de disponer de una salida al océano y de comunicación con España.

\footnotetext{
* Departamento de Geografía. UNED.
} 
Más tarde, a partir de la segunda mitad del siglo XIX, conforme se avanza en la consolidación del modelo agroexportador, el nacimiento de ciudades fue vinculado al avance de la "frontera pionera", a los fortines construidos en el enfrentamiento con los indios, como Bahía Blanca o Azul en la provincia de Buenos Aires; a la colonización agrícola de la Pampa, con la creación de centros agrícolas y de servicios, como Santa Fé en Córdoba; al tendido ferroviario, que promocionó polos de desarrollo regional; a los grandes ríos, que facilitaron la circulación y el acceso interregional, con enclaves de posición, como Rosario, y ciudades a veces enfrentadas a ambos lados de los ríos, como Corrientes-Resistencia o Encarnación-Posadas en el Paraná, y Colón-Paysandú o Salto-Concordia en el Uruguay.

Mas recientemente, el turismo ha impulsado el desarrollo de asentamientos urbanos en lugares muy diversos, en función de distintos recursos turísticos, como Mar del Plata, en Buenos Aires; San Carlos de Bariloche, en Río Negro; Punta del Este o Petrópolis en Uruguay. La función política motivó la fundación de La Plata en 1883, como capital de la provincia de Buenos Aires, con un plano que es un cuadrado perfecto de 600 ha cruzado por diagonales. La explotación minera, sobre todo petrolera, la función administrativa, la actividad portuaria y la actividad agrícola, reforzada por industrias derivadas, han dado lugar en Patagonia a núcleos dispersos, aislados y distantes entre si, como Río Gallegos, Comodoro Rivadavia, Neuquén, Viedma, Puerto Madryn.

El contrabando, el comercio fronterizo y la posición estratégica en corredores de comunicación, a orillas de ríos y al borde de carreteras, potenciados por la construcción de puentes internacionales, han originado la reciente expansión de ciudades como Pedro Juan Caballero o Presidente Stroessner, en la frontera de Paraguay con Brasil.

Las ciudades cubren así de forma desigual el territorio; se concentran en las zonas más dinámicas y de poblamiento más intenso y antiguo: frente fluvial del Plata, eje Rosario-Córdoba, región de Cuyo, noroeste y nordeste argentino, región central de Paraguay. En medio quedan enormes vacios: la franja andina, sobre todo al sur de Mendoza y norte de Neuquen; la llanura chaqueña; la mayoría de Patagonia; el interior de Uruguay y la mayor parte de Paraguay.

\section{MACROCEFALIA Y JERARQUIA URBANA}

La concentración del 90 por 100 de los flujos migratorios en el frente fluvial de la Pampa, Buenos Aires y Montevideo, durante la etapa de 


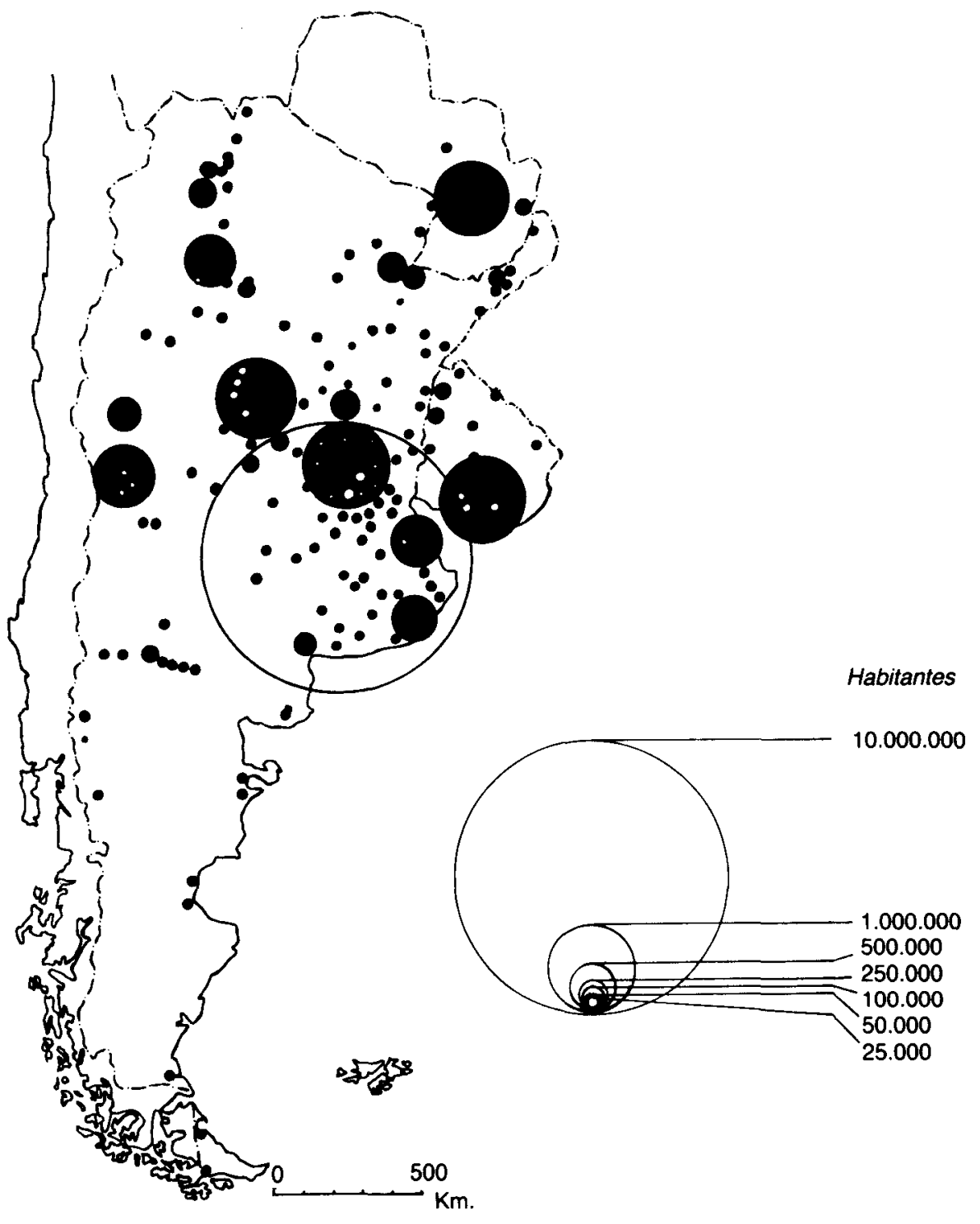

Sistema urbano 
esplendor del modelo económico agroexportador, de mediados del siglo XIX a los años treinta del nuestro, que propició el crecimiento económico y la prosperidad de Argentina y Uruguay, fueron la causa de la aparición del fenómeno de macrocefalia, incrementado posteriormente con las migraciones interiores, la industrialización y la acumulación del capital en esos mismos espacios, más Córdoba en el interior. El porcentaje poblacional de las capitales, con la mayor concentración industrial, la acumulación de las funciones terciarias públicas y privadas, y la convergencia de las comunicaciones nacionales e internacionales, ha pasado en Argentina del 16,4 por 100 en 1900 a un máximo del 39,6 por 100 en 1970 y en Uruguay del 30,3 por 100 en 1900 al 52,9 por 100 en 1970. Sólo desde la década de los setenta, disminuye ligeramente la primacia poblacional de las capitales: el 32,9 por 100 en Argentina en 1984 y el 40 por 100 en Uruguay, debido al mayor crecimiento de las ciudades intermedias y localidades próximas a las grandes aglomeraciones.

En Paraguay, la mayor parte de la población urbana se concentra también en la capital, Asunción, con 477.065 habitantes en 1985 y 798.000 habitantes si se consideran incluidos los asentamientos que integran su área metropolitana.

Desde el punto de vista de la jerarquía urbana, el Gran Buenos Aires funciona como metrópoli completa de rango superior para el conjunto regional del Plata y las otras capitales como metrópolis nacionales que cubren todas las necesidades de la población. Las ciudades intermedias, como Rosario, Córdoba, Tucumán, Mendoza, Santa Fé, Resistencia, Bahía Blanca o Comodoro Rivadavia, con funciones comerciales, financieras, asistenciales, educativas, culturales, de esparcimiento, incrementadas en ocasiones por la función político-administrativa, actuan como metrópolis regionales y podrian convertirse en ciudades de equilibrio para compensar el excesivo dominio de Buenos Aires, pero son escasas en Argentina e inexistentes en Uruguay y Paraguay, lo que agudiza los problemas de vertebración de las redes y organización del territorio.

Por debajo quedan las capitales de provincias de menor potencial económico, como Formosa, Salta o San Juan; centros regionales incompletos o secundarios, constituidos por ciudades cuyo desarrollo les ha permitido organizar la agricultura, disponer de equipamientos asistenciales y educativos adecuados, poseer algunas industrias y facilitar los intercambios comerciales a su entorno; centro locales, de 2.000 a 40.000 habitantes, en relación con las actividades agropecuarias; y pueblos, que atienden las necesidades más urgentes de extensas áreas rurales, en general aislados y mal conectados. 
A diferencia de los sistemas urbanos de los países más evolucionados, las relaciones entre los centros de distinto rango dentro de la jerarquia urbana no se realizan siempre de forma complementaria y escalonada, de los centros peor equipados a los mejor dotados, sino que con frecuencia se realizan directamente con la metrópoli regional o la metrópoli nacional, debido al carácter incompleto de las redes. Son frecuentes los fenómenos de cortocircuito, provocados por la excesiva acumulación del aparato productivo en los núcleos principales, la desmesurada centralización de las comunicaciones, el impacto de la planificación, que concentra espacialmente el crecimiento económico y prima el desarrollo de los asentamientos más consolidados, el estímulo de élites sociales arraigadas sobre la expansión urbana y la modernización del campo que propicia los contactos directos con las grandes aglomeraciones.

\section{MALLAS URBANAS REGIONALES}

Los subsistemas regionales, además de estar escasamente consolidados, mostrar reducida interacción entre si y gran dependencia del área central, repiten los desequilibrios jerárquicos existentes a escala nacional.

El subsistema pampeano es el más denso y evolucionado. Está compuesto por las ciudades del frente fluvial y marítimo y los núcleos de la Pampa agroganadera. Los centros se distribuyen regularmente en torno al Gran Buenos Aires gracias a la llanura, de modo aproximado al modelo hexagonal de Christaller que favorece la difusión del desarrollo. Aparte de Buenos Aires, destaca Rosario, que pasó de pequeño núcleo de 925 habitantes, a principios del XIX, a importante nudo ferroviario, centro industrial y universitario, puerto exportador de alcance mundial y segunda ciudad de Argentina, hoy desplazada por Córdoba.

En la zona de contacto de la llanura y las sierras Pampeanas se origina un subsistema central. Ciudades como San Francisco, Dean, Funes, Río Cuarto, Carlos Paz o Villa Maria gravitan de forma radioconcéntrica alrededor de Córdoba, como metrópoli regional que se beneficia de su posición central en el territorio, de la disposición de la red de transportes, de su tradición cultural y de un moderno desarrollo industrial favorecido por la abundancia de energía hidroeléctrica.

En torno al Gran Mendoza, en situación estratégica respecto a los pasos cordilleranos y centro de una región agricola e industrial, con recursos mineros que proporcionan variedad a su economía, aparece el subsistema Cuyano. Las ciudades se disponen longitudinalmente a 10 

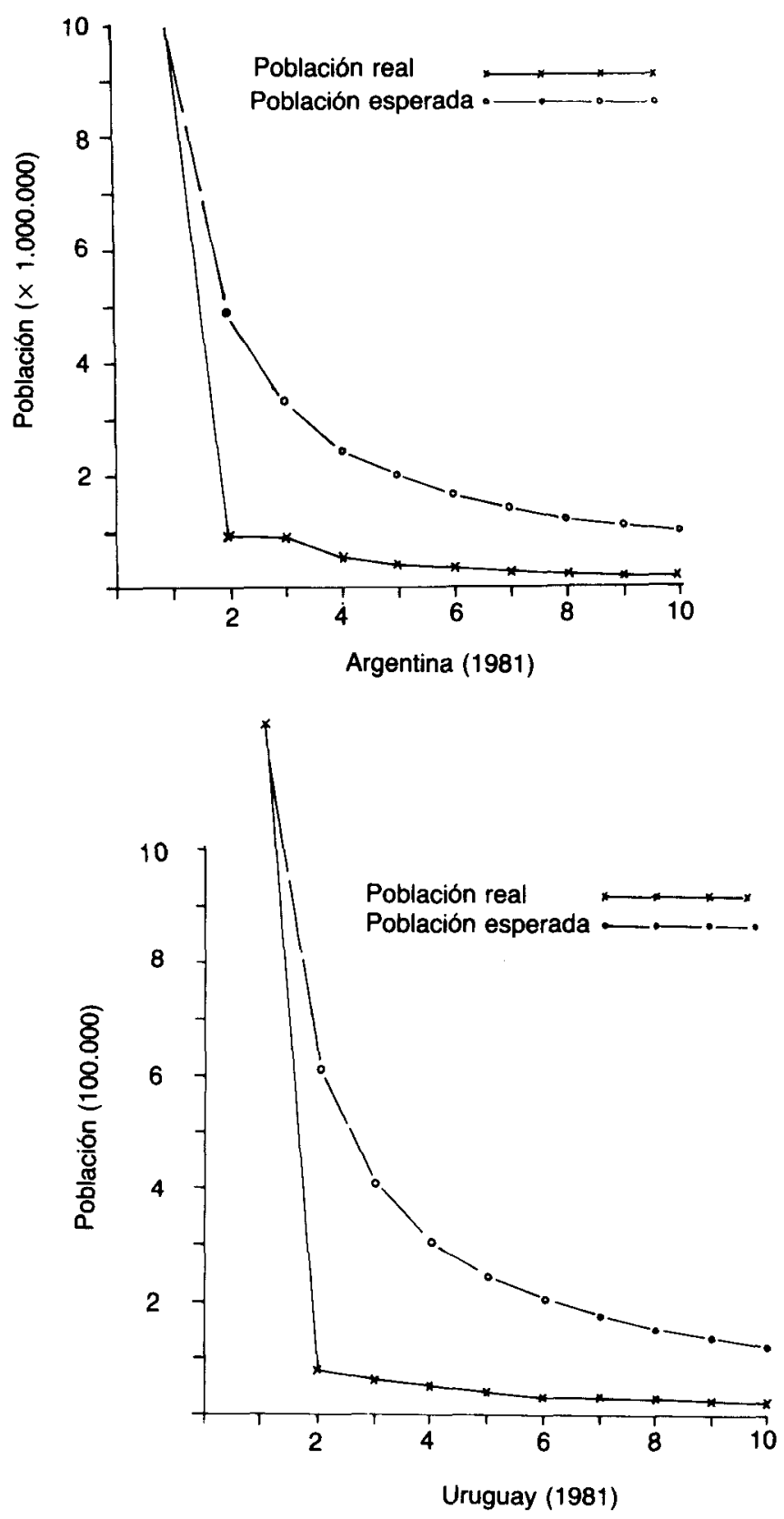

JERARQUIA URBANA

RANGO-TAMAÑO 


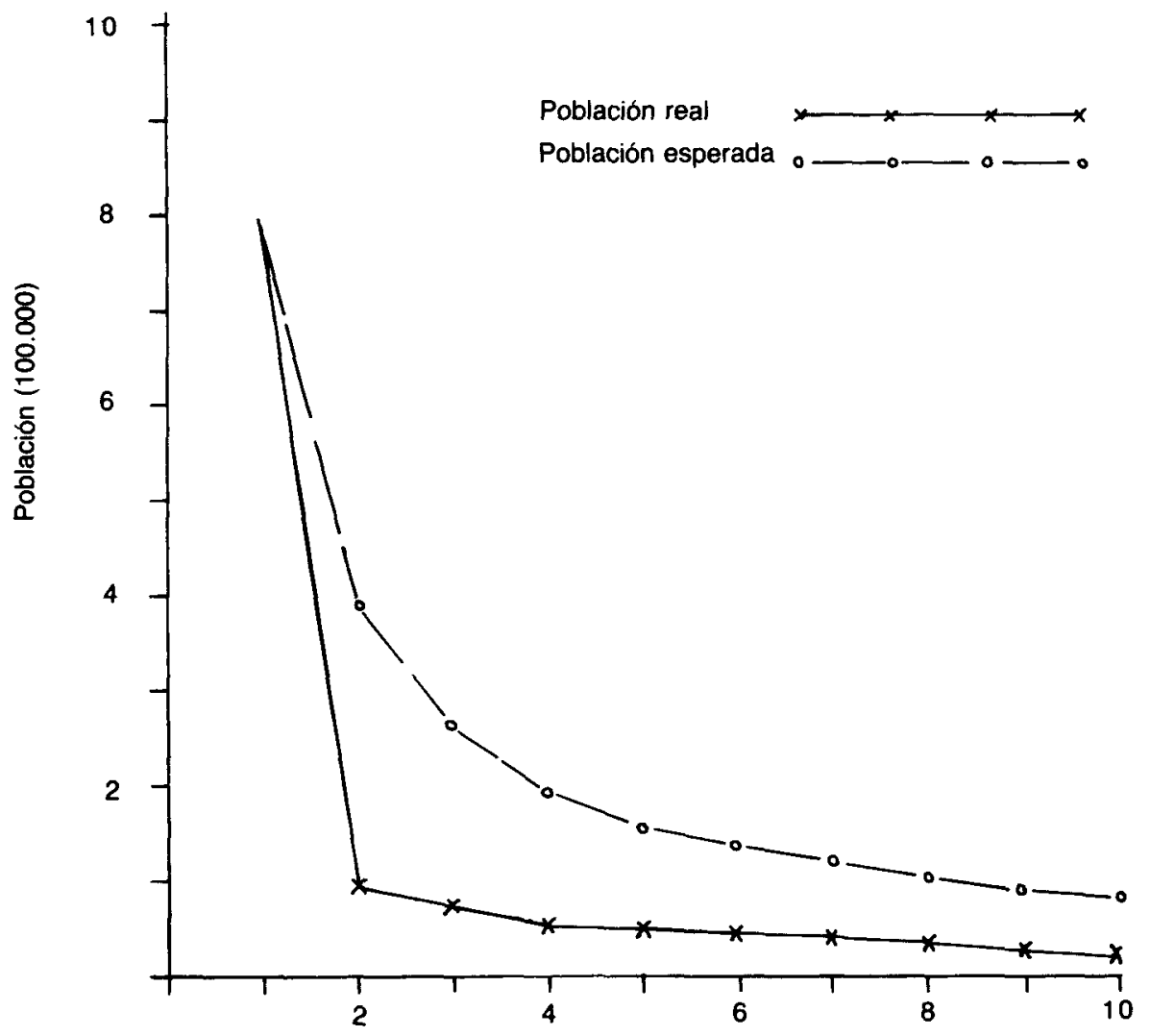

Paraguay (1982)

JERARQUÍA URBANA

RANGO-TAMAÑO 
largo del piedemonte andino, en los oasis de abundantes recursos hídricos que surgen al contacto de la montaña con la planicie, en la zona de mayor inestabilidad sísmica de la República Argentina. Aparte de Mendoza, la metrópoli Negional, sobresale San Juan.

Las ciudades del noroeste argentino, en el contacto de la Puna, la cordillera Oriental y las sierras subandinas, forman otro subsistema en torno a Tucumán como metrópoli regional. Las ciudades principales se disponen de modo lineal, a lo largo de un eje que favorece el desarrollo y las relaciones con el alto Perú y Chile, por los corredores de comunicación que forman los valles intermedios, interiores y quebradas, por donde discurrió el "camino del inca" y penetraron los españoles desde el Perú.

Tucumán, centro universitario, político e industrial, tradicional punto de enlace entre la cuenca del Plata y el alto Perú, es el núcleo rector, pero también tiene importancia Salta, ciudad de viejo sabor colonial en el valle del Lerma, a $1.226 \mathrm{~m}$ sobre ei nivel del mar, y San Salvador de Jujuy, en la confluencia de los ríos Chico y Grande de Jujuy.

En el nordeste, Posadas, Formosa, San Roque, Peña, Goya, Reconquista son centros secundarios, sobre ríos y vías de circulación, que integran un subsistema urbano de morfología anular, alrededor de Resistencia-Corrientes, núcleo bipolar, como metrópoli regional. No obstante, la cohesión y relaciones de jerarquía urbana son débiles por la competencia de las grandes aglomeraciones pampeanas sobre las ciudades meridionales de la provincia de Corrientes, por la atracción del movimiento generado entre Misiones y la Pampa sobre los asentamientos del río Uruguay, y por el creciente papel de Posadas como núcleo rector y organizador del territorio de Misiones, favorecido por una posición privilegiada entre su hinterland y los principales centros de producción y consumo del país, a diferencia de Resistencia-Corrientes.

Dentro de este subsistema, en la provincia de Misiones, de primitivo poblamiento guarani, perviven los vestigios de los antiguos pueblos y reducciones jesuíticas. El más importante es el de San Ignacio Mini, declarado recientemente Patrimonio de la Humanidad por la UNESCO y convertido en centro turístico.

Las duras condiciones del medio físico, la escasez de población y la insuficiencia de infraestructuras explican la escasa cobertura regional de las ciudades de Patagonia. Como corresponde a frentes de colonización y ocupación pionera, sólo existen subsistemas embrionarios, de morfología variada y sin articulación ni relación entre ellos. Los centros se localizan en el valle del Río Negro; en el curso bajo del Chubut; en el 
piedemonte y valles andinos; alrededor del Golfo de San Jorge, por la explotación del petróleo; en el sur de la provincia de Santa Cruz, por la extracción de carbón; y en Tierra del Fuego.

La organización de las comunicaciones en función de Buenos Aires y la carencia de poder económico de los núcleos urbanos hacen que ninguna ciudad tenga capacidad suficiente para vertebrar el territorio como metrópoli regional.

$\mathrm{Ni}$ en Uruguay ni en Paraguay existen subsistemas urbanos regionales, tan sólo las capitales, Montevideo y Asunción, constituyen verdaderas aglomeraciones y tienen medios para estructurar una red urbana.

\section{EL MOSAICO URBANO. MORFOLOGÍA Y ESTRUCTURA}

Las tasas de crecimiento urbano (del 1,94 por 100 en Argentina, 0,93 por 100 en Uruguay y 4,20 por 100 en Paraguay en 1990) muy superiores a las del campo y a las de la población en general, por la concentración de los flujos migratorios transoceánicos en las ciudades, la movilidad reciente entre ciudades de distinto rango y países vecinos, y el éxodo rural, repercuten en la organización interna del espacio urbano y provocan graves problemas de alojamiento, transporte y medioambientales.

La morfologia y estructuras urbanas, con rasgos comunes al modelo latinoamericano, resultan de la combinación de elementos culturales propios y elementos modernizadores del proceso de urbanización capitalista que se manifiestan en las contradicciones centro-periferia y arquitectónicamente en una edificación que en Buenos Aires y Montevideo recrean la imagen de Madrid, París o Londres, aunque tampoco faltan rascacielos de 30 o 40 pisos al estilo de las aglomeraciones norteamericanas.

Las ciudades se caracterizan por su trazado en damero; edificación de escasa altura excepto en el centro; existencia de áreas centrales históricas que incluyen el núcleo fundacional y concentran actividades de gestión, dirección e intercambio y slums; una espina que prolonga sectorialmente hacia el exterior los rasgos del centro de actividad; asentamientos industriales periféricos o en posiciones centrales incómodas por la antigüedad de la industrialización y la expansión urbana; áreas residenciales de composición social y morfológica diferenciadas en disposición concéntrica de mayor a menor calidad del centro a los bordes; y proliferación de asentamientos marginales. 
La trama ortogonal, con una plaza mayor donde se ubican los edificios públicos y se concentran los poderes: catedral, cabildo, palacio gubernamental, comercio, al estilo de la plaza de Mayo de Buenos Aires o de la plaza de la Constitución de Montevideo, es la principal herencia colonial. Recoge la tradición urbana clásica, recuperada por el renacimiento y difundida por los españoles en América a través de sus primeras fundaciones y de las Nuevas Ordenanzas de Población (1573), dentro de las Leyes de Indias. Desde finales del XIX, las ciudades nacidas del ferrocarril, las colonias y pueblos agrícolas, las ciudades de recreo, como Mar del Plata, y la ciudad administrativa de la Plata, fundada como capital de la provincia de Buenos Aires tras la designación de la ciudad de Buenos Aires como capital federal en 1880, consolidaron este urbanismo. Las únicas novedades fueron la mayor amplitud en el trazado de las vías, la proliferación y jerarquización de plazas, y la introducción de diagonales en los planos ortogonales de ciudades nuevas como Almirante Brown, ciudad de recreo trazada en 1872, en ciudad de la Plata, y en obras de reforma interior, como las que dieron lugar a las calles de Roque Saenz Peña y Julio A. Roca en Buenos Aires, dentro del Plan de 1910 que completaba el de 1880.

$\mathrm{Al}$ igual que en los paises industrializados, las áreas centrales de las grandes aglomeraciones concentran el comercio, las finanzas, la administración y el esparcimiento, mientras las funciones residencial e industrial son desplazadas a la periferia. Hoy, constituyen verdaderos espacios problemas. Se hallan sometidos a procesos de vaciamiento y envejecimiento, a la formación de slums, zonas de deterioro material y degradación social, al desarrollo de fenómenos de invasión-sucesión funcional y social, y a actuaciones de renovación que buscan un aprovechamiento intensivo del suelo, con crecimiento tridimensional, por la competencia de actividades financieras, de gestión y dirección que pugnan con otros usos por localizaciones centrales. La escasez de inversiones en transportes públicos provoca la insuficiencia y deterioro de los existentes, como ocurre con el metro bonaerense, el primero construido en Latinoamérica, en 1914, y durante mucho tiempo el único. La estructura monocéntrica de las ciudades y la estrechez de las calles en Buenos Aires $(6 \mathrm{~m}$ y 9,50 $\mathrm{m}$ ) agravan las dificultades de circulación y contribuyen a la congestión del tráfico. Sólo constituyen una excepción las ocho grandes avenidas, de $26 \mathrm{~m}$ que parten del río y se despliegan en abanico hasta los confines de la ciudad; las dos avenidas diagonales, de $30 \mathrm{~m}$, que parten de la plaza de Mayo; y la Avenida de Julio. Todas ellas fueron construidas según las directrices de los planes de reforma interior de 1880 y 1910 que pretendian airear el viejo damero según patrones culturales proce- 


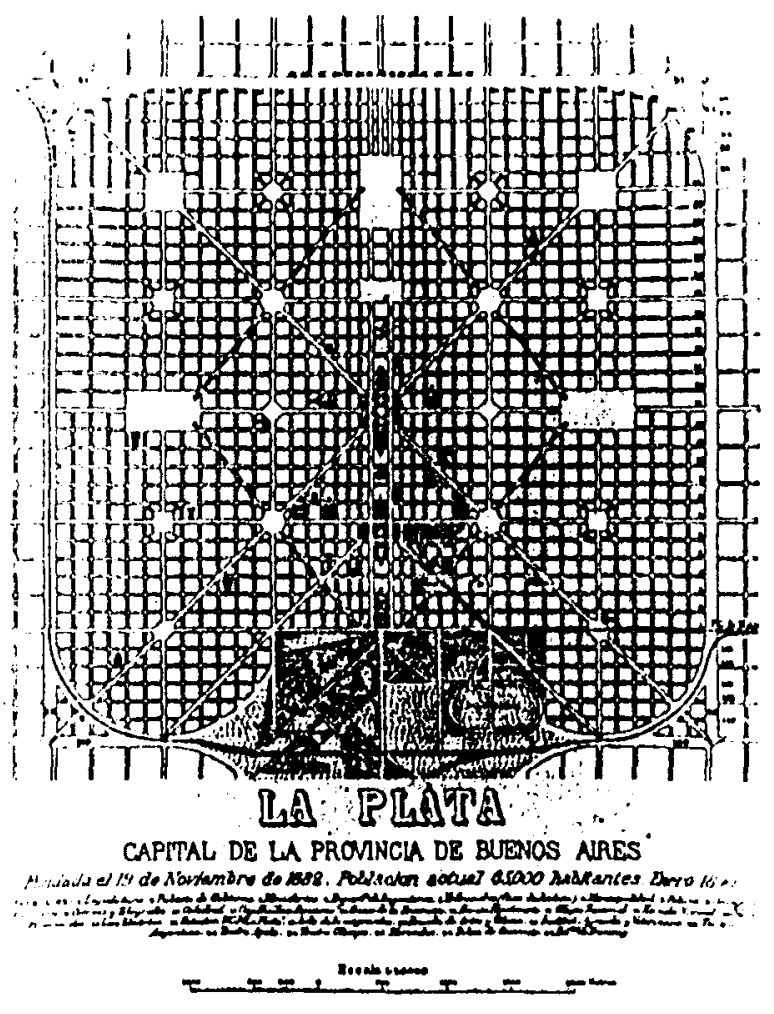

dentes de Francia a través de especialistas de este origen, entre los que destaca Bouvard.

Forestier en los años 20 y el arquitecto Noel, coordinador del denominado Plan de Estética Edilicia que empezó a aplicarse a partir de 1925, contribuyeron también a imponer modos de producir y vivir la ciudad según modelos franceses.

En los centros históricos cobran intensidad creciente procesos de degradación y deterioro material, como en Montevideo, ubicado en una península de reducida superficie, con escasas inversiones productivas y descenso poblacional; y procesos contrarios de recuperación por clases sociales de rentas altas que substituyen a residentes autóctonos dentro de un fenómeno general de reurbanización. El pequeño centro histórico 


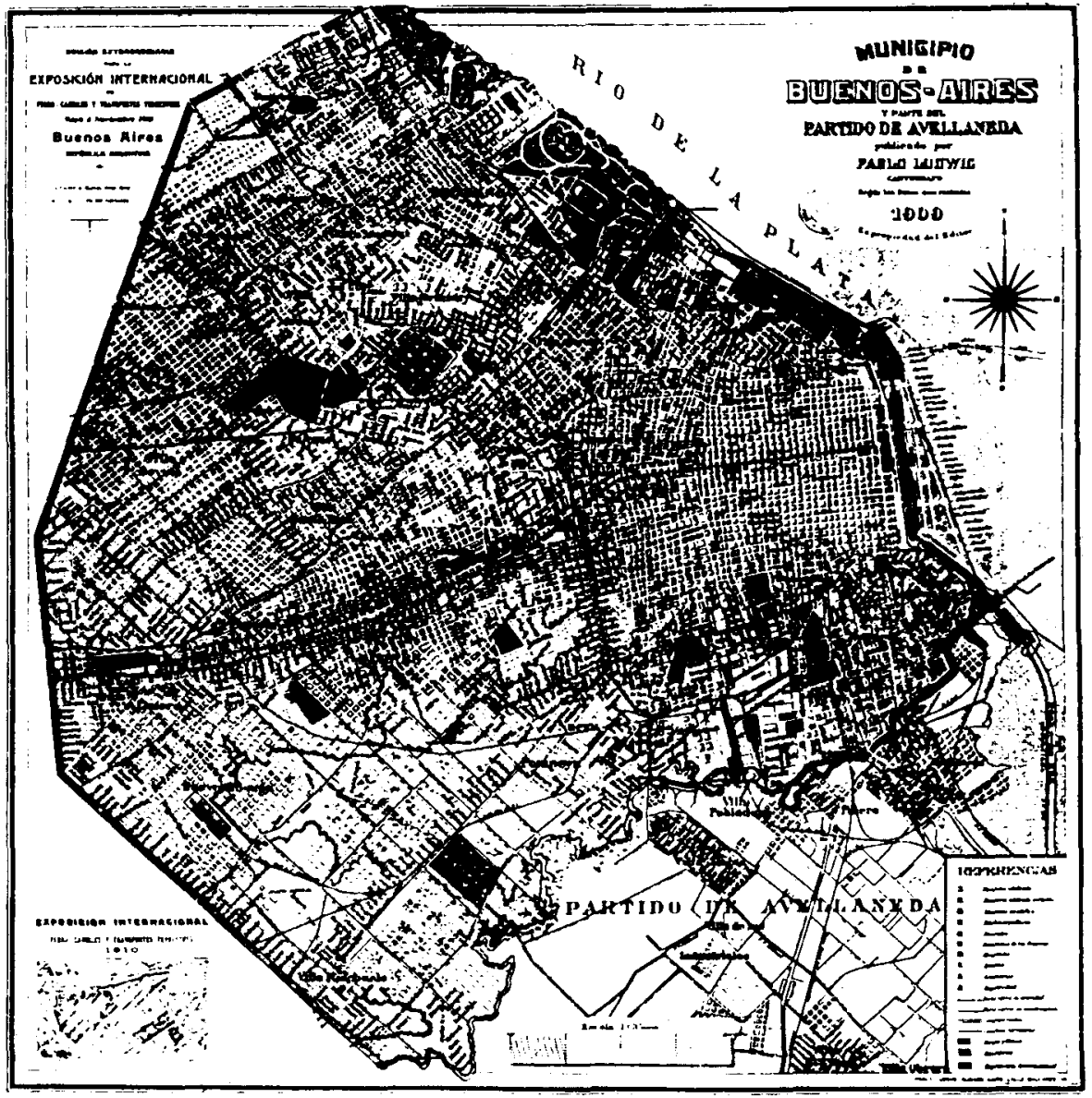

PLANO DE BUENOS AIRES EN 1909 
de Colonia del Sacramento, en Uruguay, es en la actualidad residencia temporal de familias con ingresos comparativamente altos, sobre todo argentinas, que pasan en él vacaciones y fines de semana, favorecidas por la proximidad a Buenos Aires. El barrio de San Telmo, al sur de Buenos Aires, lindante con el centro de actividad, atrae a artistas y profesionales, comercios especializados, sobre todo anticuarios, restaurantes, lugares de esparcimiento nocturno y librerías. De modo análogo, el barrio de Palermo viejo ha sido rehabilitado por profesionales y empresarios.

La expansión de la ciudad, con procesos de suburbanización y metropolitanización que desbordan los tradicionales límites administrativos y la capacidad de atender convenientemente las necesidades urbanas, favorecen la formación de espinas rodeadas del sector residencial de mayor categoría. Prolongan hacia la periferia actividades propias del centro de actividad y concentran infraestructuras, parques, museos, transportes. Constituyen la respuesta a la limitada capacidad de los poderes públicos de extender servicios y equipamientos a toda la ciudad por su crecimiento espectacular. En Montevideo, la espina y el sector residencial de mayor calidad se desarrollan desde el centro de actividad (casco antiguo y ejes Libertador y Dieciocho de Julio) por la avenida de Italia y playas urbanas hacia el aeropuerto y Punta del Este, mientras en Buenos Aires lo hacen desde la plaza de San Martín hacia el norte por las Recoletas, Palermo y Belgrano, alrededor del demolido palacio y jardín del presidente Rosas, siguiendo el eje de la avenida del Libertador. Es un sector de barrios elegantes con parques que pretenden recrear el ambiente del West-End de Londres y del Oeste de Paris y se prolongan por el Norte hasta los distritos de Vicente López y San Isidro.

En torno al centro de actividad, se disponen áreas residenciales de categoría social y morfológica decreciente del interior al borde urbano: zona de madurez, integrada por barrios consolidados, población de edad avanzada y bien dotados de equipamientos y servicios urbanos; zona de autoperfeccionamiento, con una gran diversidad habitacional y escasas dotaciones colectivas y de infraestructuras; y zona de asentamientos marginales 0 inestables, carentes de abastecimiento de agua potable, de saneamiento y eliminación de residuos, sobre suelos ocupados ilegalmente en emplazamientos inapropiados que afectan a las condiciones de salud de sus moradores.

Las villas inestables o villas miserias empiezan a surgir en las periferias urbanas del frente del Plata en los años veinte, cuando los conventillos o casas de vecindad de las áreas centrales resultan insuficientes para alojar a las masas de población que afluian a través de las grandes 


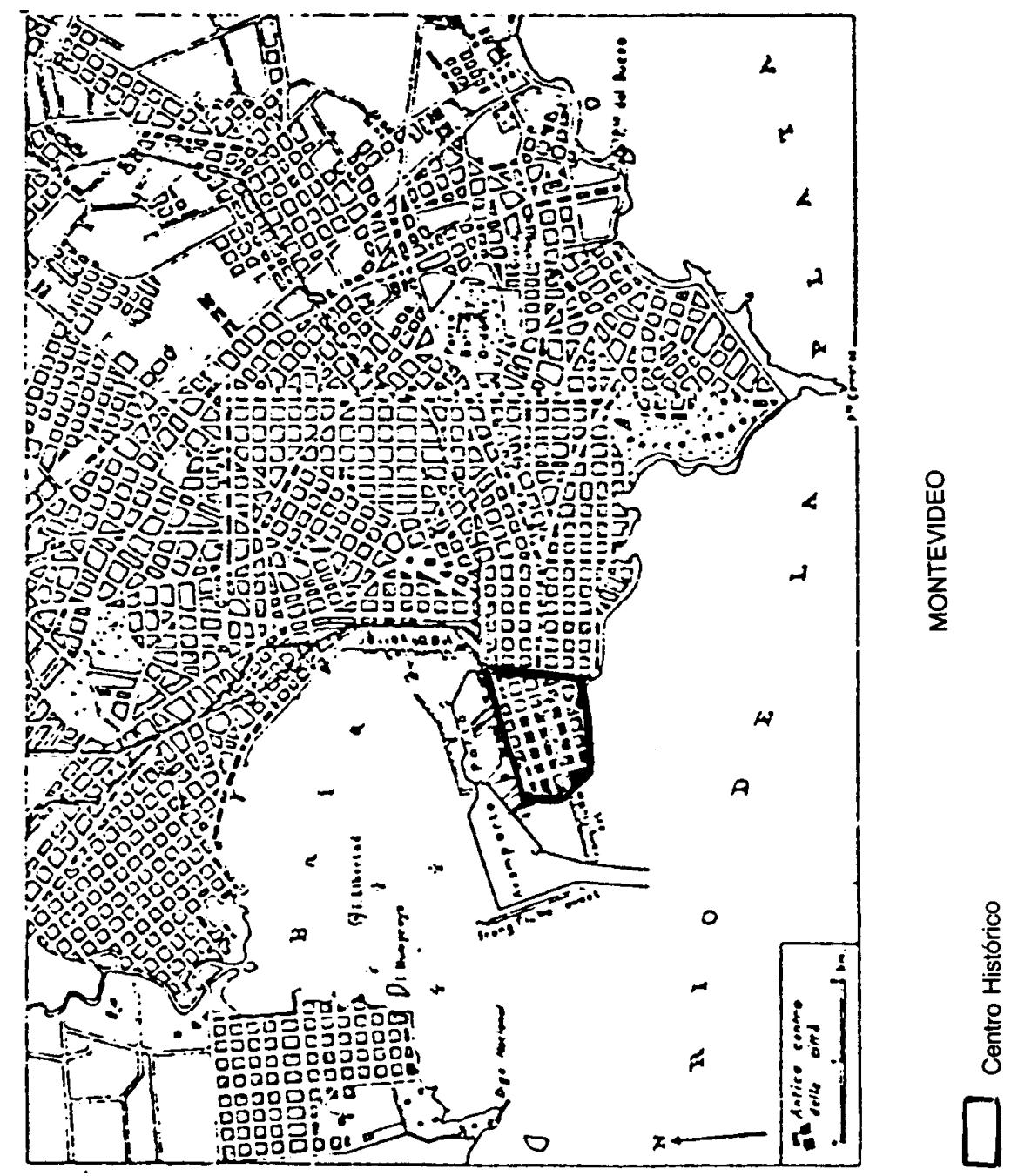


migraciones. En 1904, el 14 por 100 de la población de Buenos Aires residía en conventillos, en condiciones de hacinamiento e insalubridad, más de tres personas por pieza, que favorecian el alcoholismo, la tuberculosis y el nacimiento de epidemias de viruela, fiebres tifoideas y difteria. La mayoría se localizaban en el centro, en los barrios de San Telmo, Socorro y La Boca. Hoy, los conventillos han desaparecido prácticamente, pero el crecimiento urbano provocado por la industrialización posterior a 1945, las migraciones desde países vecinos, el éxodo rural, el alto precio de los alquileres y la incapacidad de la economía de mercado y de la política del Estado para proporcionar alojamiento y servicios públicos urbanos adecuados, han provocado un enorme déficit de viviendas que ha hecho proliferar los asentamientos marginales en Argentina. Circunstancias análogas explican el desarrollo de las villas inestables en las periferias de las ciudades principales de Uruguay y Paraguay, sobre todo en las áreas metropolitanas de Montevideo y Asunción.

A los problemas de insalubridad y marginalidad de estos asentamientos, ocasionados por las condiciones de alojamiento a sus moradores, se añaden los que se derivan de sus emplazamientos, cada vez más alejados del centro, 10 que repercute en las dificultades de transporte y comunicación con el resto de la ciudad, y los de contaminación estética y deterioro de su entorno inmediato. Por eso, durante mucho tiempo, la política de los poderes públicos se dirigió a su eliminación, en un urbanismo convulsivo y superado que lo único que conseguía era su erradicación de las áreas centrales, en beneficio de usos del suelo intensivos, para reproducirse en periferias más alejadas, como sucedió en Buenos Aires con el gobierno de los militares, de 1976 a 1983, o en Mendoza y otras ciudades argentinas en 1978 con ocasión de la realización del Campeonato Mundial de Fútbol.

Las instalaciones industriales configuran extensas áreas urbanas y periurbanas en las ciudades del frente de la Pampa húmeda, entre San Lorenzo y Ensenada, donde se concentra el 90 por 100 del producto bruto industrial, favorecido por la disponibilidad de agua potable y energía eléctrica de distinto origen, entre ella la procedente de la central nuclear de Atucha, la primera de Latinoamérica, la existencia de puertos de fácil acceso, la abundancia de mano de obra y la gran dimensión de su mercado de consumo, la concentración de las actividades productivas impulsadas por los planes quinquenales de 1947-52 y 1953-57, y por la concentración de las industrias básicas y metalúrgicas de transformación desarrolladas en los años cincuenta y sesenta.

La principal concentración de industrias se localiza en el Gran Buenos Aires. Los primeros suburbios industriales surgen en el sur y su- 
roeste, en los barrios populosos y de inmigrantes de la Boca, Barracas, San Cristóbal, Avellaneda, Quilmes y Lomas de Zamora, a partir de los depósitos, mataderos, frigoríficos e industrias de primera generación que se instalaron entre 1896 y 1923 en las inmediaciones del puerto y del Riachuelo. Después, con el posterior proceso de industrialización, se han extendido hacia el Noroeste, de Morón al bajo Paraná, por Tigre, con importantes astilleros, y hacia las ciudades de Campana y Zárate.

Hoy, los primeros suburbios industriales han quedado en una posición central e incómoda. Muchas de sus instalaciones se han convertido en barbechos industriales, a la espera de usos más intensivos del suelo, y otras siguen funcionando pero con los inconvenientes de su envejecimiento y de las deseconomías de aglomeración. No obstante, las dificultades económicas y el peligro a aumentar el paro y el desempleo han frenado su traslado a otros emplazamientos fuera de la ciudad.

En otras ciudades del interior, como Córdoba, Mendoza, San Juan, o del frente marítimo, como Bahía Blanca o Mar del Plata, de industrialización más reciente, las fábricas se localizan espontáneamente en áreas centrales o de forma más organizada y segregada en parques industriales, dentro del modelo de ciudad zonificada que se impuso en el mundo entero a partir de la difusión de la "Carta de Atenas" y de las obras de Le Corbusier. Además, hay que tener en cuenta la influencia directa del propio Le Corbusier en Latinoamérica, al intervenir directamente en la elaboración de planes de urbanismo para diversas ciudades, entre las que figuran Buenos Aires, Río de Janeiro y Bogotá.

En Montevideo, que también concentra la mayor parte de las industrias de Uruguay, las instalaciones se disponen al borde de la bahía y de modo radial, en las carreteras de acceso a la ciudad hasta una distancia de 30 ó $40 \mathrm{~km}$ del centro, en función de su diferente antigüedad y características en cuanto a dependencia de materias primas que llegan por mar o de relación con el entorno, como sucede con las agroindustrias.

Asunción, por su parte, añade a sus funciones políticas, como capital del Estado, comerciales y financieras, el desarrollo creciente de numerosas industrias en la periferia y junto al río Paraguay; sobre todo de alimentación, refino de petróleo, químicas y textiles.

\section{INEFICACIA DE LA PLANIFICACIÓN URBANA}

La consolidación de sistemas urbanos de morfología concentrada, que dificultan la integración del aparato productivo y la vertebración terri- 
torial, con enormes vacíos intermedios, y el deseo de controlar el crecimiento de las grandes aglomeraciones, fuerzan a los poderes públicos a políticas de planificación e intervención. Sin embargo, estas actuaciones difícilmente tienen éxito por la magnitud y gravedad de los problemas, la insuficiencia del planeamiento y la escasez de objetivos sociales. En general, los resultados son mínimos y la frustración de los planificadores es grande.

Por una parte, se estimula la ocupación de la región patagónica y del interior mediante regímenes promocionales de las actividades económicas; desde 1966 se obliga a los municipios en Argentina a disponer de una oficina de "planeamiento y desarrollo" y a elaborar planes urbanos; se realizan programas para las ciudades intermedias y para el desarrollo local; se plantean actuaciones de complementación e integración entre los paises del Plata; y se aprueba por Ley, en 1987, el traslado de la capital federal a una nueva ciudad en Patagonia, en un lugar entre Viedma, Carmen de Patagones y el mar.

Por otra parte, a partir de los años sesenta, se crean áreas metropolitanas según modelos anglosajones de postguerra y se acometen programas para su ordenamiento y coordinación que son desbordados por la gravedad de los problemas, las dimensiones de las aglomeraciones, superiores a las de las áreas metropolitanas, y la falta de articulación entre las diferentes autoridades encargadas de organizar las ciudades. Esto es precisamente lo que sucede de forma acusada en el Gran Buenos Aires, donde se superponen políticas urbanas nacionales, provinciales y municipales contradictorias sobre un espacio central dependiente de su propia municipalidad y una periferia vinculada administrativamente a la ciudad de La Plata, capital provincial que no forma parte del área metropolitana bonaerense.

La planificación urbana se ha visto dificultada por la falta de planes de urbanismo a nivel nacional que permitieran integrar convenientemente los planes locales y por la ausencia de objetivos sociales, incluso con regímenes constitucionales reformistas o populistas, como en Argentina en los períodos 1963-66 o 1973-76. La concepción de la ciudad como producto de agentes sociales con intereses, necesidades y posibilidades contrapuestas, no está presente en la planificación urbana de los países del Plata. En general, las propuestas de intervención se han hecho en beneficio de intereses políticos dominantes y de sectores económicos privilegiados; se han dirigido a realizar inversiones para suplir deficiencias locales, a "legalizar» áreas ya ocupadas por usos comerciales e industriales, a favorecer usos intensivos del suelo en espacios centrales o a preservar áreas residenciales de rentas altas, potenciando la segregación 
ecológica de la ciudad. La población no es consultada en la planificación y con frecuencia los efectos han sido desastrosos para los niveles de renta más bajos; son escasas las ocasiones de participar a través de organizaciones profesionales o de barrio.

Los planes locales de ordenación urbana, concebidos a menudo con grandes expectativas, no se llevan a término; tratan superficialmente aspectos económicos, sociales, legales, ambientales, políticos e institucionales, y sus enfoques son con frecuencia excesivamente sectoriales sin tener en cuenta su repercusión en el sistema global urbano. Actuaciones espectaculares, como las acometidas en Buenos Aires entre 1977 y 1983, con los militares en el poder, destinadas a reforzar el centro de negocios y los barrios residenciales próximos, no consiguieron sus objetivos más que de modo parcial y a un alto coste social, como fue la expulsión de clases populares del centro. Las contradicciones centro-periferia se agudizaron con la erradicación de las villas miserias del interior de la ciudad y el desalojo de gran parte de "conventillos". La disminución de los índices de ocupación y el aumento del valor de los inmuebles favorecieron la "elitización" del centro. Mientras, las autopistas intraurbanas, construidas entonces, no han solucionado los problemas de accesibilidad al centro al ser apenas utilizadas por su elevado precio de peaje. 


\section{BIBLIOGRAFÍA}

Bacigalupo, J. L., 1969: “Proceso de Urbanización en la Argentina». En Hardoy, J. E. y Tobar, C (dir). La urbanización en América Latina. Buenos Aires, Editorial del Instituto, págs. 389-417.

Bradbury, K. L.; Bouns, A.; Small, K. A., 1982: Urban decline and the future of american cities. Washington, D.C., The Brookins Institution, 309 páginas.

Clichevsky, N. y Rofman, A., 1989: "Planificación regional y urbana en la Argentina. Una revisión crítica", Ciudad y Territorio, n. ${ }^{\circ}$ 79-1, págs. 61-71.

DiefrieRI, H., 1981: Buenos Aires, Geohistoria de una metrópoli. Universidad de Buenos Aires, 152 páginas.

GrifFin, E. y LARRY, F., 1980: A model of Latin American City Structure. Geographical Review, 70, págs. 397-422.

Kollmann DE CuRuchet, M., 1973: Teoria sobre el sistema de ciudades y su aplicación a la Argentina. Serie Especial, n. ${ }^{\circ} 1$. Tomo de homenaje a Romualdo Ardissone. Sociedad Argentina de Estudios Geográficos, Buenos Aires.

PAJONI, R., 1983: “Buenos Aires, 1976-1982. La ségrégation compulsive», en Hérodote, n. ${ }^{\circ} 31$, págs. 38-61.

Roccatagliata, J. A. y Beguiristain, S., 1988: «Urbanización y sistema urbano", en La Argentina. Buenos Aires, Ed. Planeta, págs. 323-344.

SolANo, F., DE 1985, Coord.): Historia y futuro de la ciudad Iberoamerican. Madrid, C.S.I.C., 183 páginas.

Vicó RosA, E., 1988: "Reflexiones acerca de la urbanización de Uruguay», en Temas Geográficos, año 1, n. 3 , Montevideo. Asociación de Geógrafos Universitarios del Uruguay, págs. 33-46.

YuJNovskY, O., 1983: «Del conventillo a la villa miseria», en Romero, J. L. y Romero, L. A. (dir). Buenos Aires, historia de cuatro siglos, II, págs. 451-464. 
ZARATE, A., 1989: "Notas sobre el modelo urbano latinoamericano", en Espacio, Tiempo y Forma, Serie VI, Geografía, t. 2. UNED. Madrid, págs. 267-290. 